\title{
STUDIES ON THE CREATINURIA DUE TO METHYLATED STEROIDS ${ }^{1}$
}

\author{
BY LAWSON WILKINS AND WALTER FLEISCHMANN
}

\author{
(From the Department of Pediatrics, Johns Hopkins University School of Medicine, and the \\ Harriet Lane Home of the Johns Hopkins Hospital, Baltimore)
}

(Received for publication April 10, 1944)

We reported in 1941 that the oral administration of methyl testosterone caused a marked increase of creatine excretion in sexually undeveloped dwarfs (1). Simultaneously, Samuels, Henschel, and Keys (2) discovered that the same effects occurred in normal men. Since then Tager (3), Werner and West (4), and others $(5,6,7)$ have observed that creatinuria followed the use of methyl testosterone in various conditions. The present paper deals with further studies we have made to determine the nature of the changes which occur in the creatinecreatinine metabolism.

\section{METHODS}

The observations we are reporting were made principally on sexually undeveloped dwarfs between the ages of 11 and 22 years because we were at the same time studying the protein anabolic effects of steroids in this 'group of patients. It is probable that the dwarfism and sexual infantilism were due to pituitary deficiency in most instances, although this diagnosis cannot be proved in all cases. The fact that methyl testosterone has identical effects on the creatine metabolism in normal individuals and in patients of either sex suffering from other disturbances has been amply demonstrated by Samuels, ourselves, and other workers.

All patients received "low creatine" diets containing no meat or fish, and not over $1000 \mathrm{ml}$. of milk daily, furnishing $30 \mathrm{mgm}$. or less of creatine. During each study, the diet was constant in respect to the content of protein, carbohydrate, and fat. Twenty-four-hour specimens of urine were collected over dilute $\mathrm{HCl}$ and analyzed daily by the method of Benedict and Myers (8), using a Klett photoelectric colorimeter for the readings.

\section{RESULTS}

Effect of methyl testosterone on the excretion of creatine and creatinine

In Figure 1 are shown the number of mgm. of creatine and of creatinine excreted daily by 11

\footnotetext{
1 This work was made possible by a grant from the Commonwealth Fund for the study of endocrine problems in childhood, supplemented by the John Howland Memorial Fund and a donation from Dr. Benjamin Baker
}

patients who received daily $25 \mathrm{mgm}$. of methyl testosterone by mouth for varying periods of time. The control periods (the starting point of each curve) were calculated as the average of the 10-day period immediately preceding treatment. We were especially interested in determining what changes occurred during the early stages of treatment. In presenting the results of the first 24 days of treatment, we employed the method of "sliding averages" using 5-day periods to compute the daily outputs. By this method, the average of days 1 to 5 inclusive are shown as the output for the third day, which is the middle of the period; the average of days 2 to 6 inclusive are recorded as the 4th day; 3 to 7 as the 5 th day, etc. ${ }^{2}$ The values recorded for the excretion after the first month of treatment are averages for periods of 10 days or longer. To emphasize the early changes, the time intervals of one day are shown on the abscissae of the chart for the first month; but to conserve space, the same interval represents one month in the remainder of the chart. This causes the rise in the curve of excretion after the first month to appear more abrupt than it actually is.

It is seen from this chart that after treatment with methyl testosterone is begun there is a latent period varying from approximately 4 to 16 days before the excretion of creatine increases. During this period, the output of creatine apparently decreases in some cases. The creatinine curves are more irregular than those of creatine, but in many instances, there also appears to be a decreased output during the early period of

(Col. U. S. A.). The contents of this paper have been reported from time to time in the minutes of the Committee on the Metabolic Aspects of Convalescence.

2 By this means, the general trend of the curve is more clearly shown because the large fluctuations from day to day are eliminated. From the 12th to the 24th days, the curve is based on a steadily diminishing group of cases. 


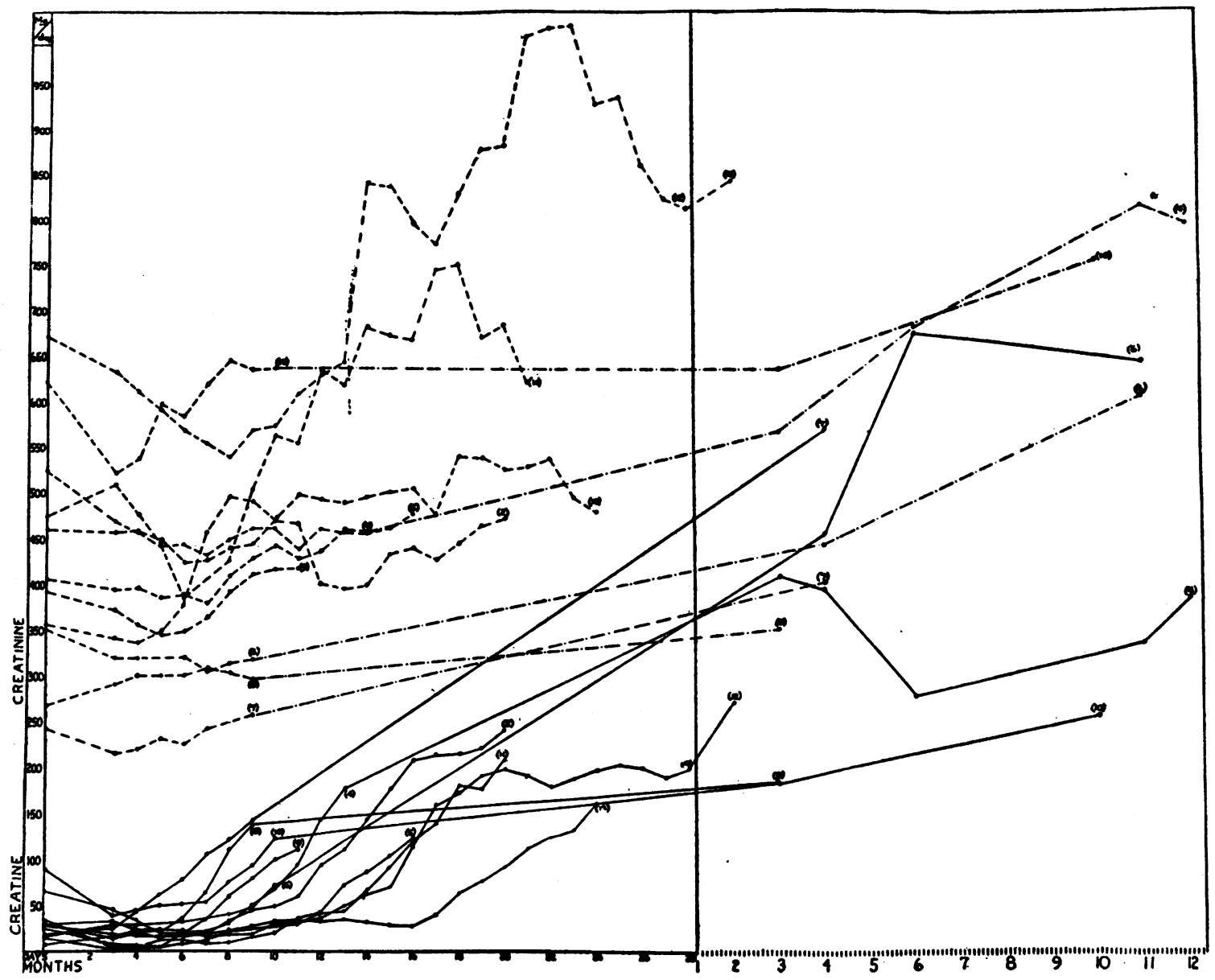

Fig. 1. Creatine-Creatinine Excretion of Patients During Treatment with Methyl Testosterone (Individual Curves)

treatment. Curves have not been drawn for the total creatinine (creatinine and creatine), but both the decreases and increases in the individual cases expressed as mgm. of total creatinine excreted daily are larger than are those of creatine or creatinine alone.

Figure 2 presents composite curves, to show the trend of excretion of creatine and creatinine during treatment. In order to compare the effect in patients of different weights, all values were reduced to the number of mgm. per $\mathrm{kgm}$. of body weight excreted daily. The shaded areas represent the range between the maximum and minimum values observed. The central heavy lines show the trends of excretion. During the first 24 days, there were sufficient numbers of cases to permit the drawing of this curve from actual averages. After this time of treatment, observations were obtained on only a few cases. These are shown in Table I.

It is obvious that these data are insufficient to represent a sample of curves so that averages could be derived from them to continue the curve of the trend shown on the chart for the first 24 days. However, an analysis of all the cases made by Dr. Christopher Tietze of the Johns Hopkins School of Hygiene and Public Health indicates that from the 24th day until about the 4th month there continued to be a marked increase in the creatine excretion, which, however, was less rapid than during the earlier period of treatment. Between the 4th month and the 12th month the increase was only very slight. The creatinine excretion showed some- 


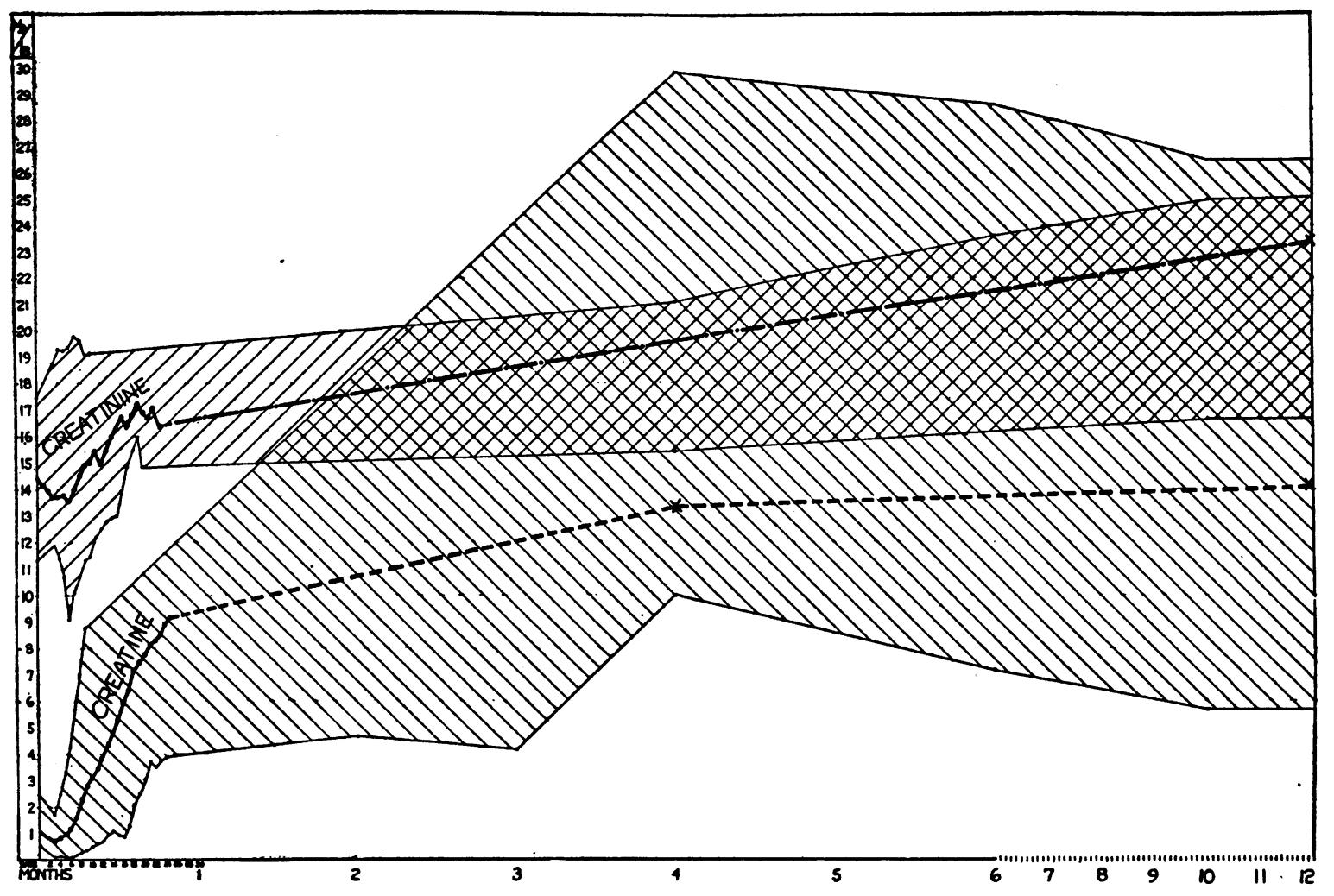

Fig. 2. Creatine-Creatinine Excretion During Treatment with Methyl Testosterone

what the same trend. After the 24th day there was a gradual constant increase. The total increase of creatinine was much less than that of creatine. The continuation of the heavy lines in the figure (in form of dashes) are to be interpreted as a reasonable presentation of the trend of excretion during these long periods of treatment rather than as exact averages of amounts excreted. It is apparent that the ratio of creatine to creatinine, which was approxi- mately 1 to 14.5 before treatment, changed considerably. The creatine output approached that of creatinine and in some cases between the 3rd and 6th month creatine exceeded creatinine as shown in Figure 1.

\section{Effect of withdrawal of methyl testosterone}

In 6 patients, observations were made on the creatine and creatinine excretion after discontinuing methyl testosterone. One patient had

TABLE I

Excretion of creatine and creatinine during treatment with methyl testosterone

\begin{tabular}{|c|c|c|c|c|c|c|c|c|c|c|}
\hline \multicolumn{6}{|c|}{ Daily creatine output } & \multicolumn{5}{|c|}{ Daily creatinine output } \\
\hline & $2 \mathrm{mos}$. & 3 mos. & 4 mos. & $6 \mathrm{mos}$. & 10 to $12 \mathrm{mos}$. & 2 mos. & 3 mos. & 4 mos. & 6 mos. & 10 to $12 \mathrm{mos}$. \\
\hline $\begin{array}{lr}\text { Case No. } & 7 \\
\text { Case No. } 12 \\
\text { Case No. } 4 \\
\text { Case No. } 8 \\
\text { Case No. } 10 \\
\text { Case No. } 6\end{array}$ & $\begin{array}{l}6.8 \\
4.8\end{array}$ & $\begin{array}{r}10.3 \\
10.1 \\
4.1\end{array}$ & $\begin{array}{c}29.9 \\
29.9 \\
10.0 \\
20.1\end{array}$ & $\begin{array}{r}7.2 \\
28.6\end{array}$ & $\begin{array}{r}8.9 \\
5.6 \\
26.5\end{array}$ & $\begin{array}{l}14.6 \\
13.1\end{array}$ & $\begin{array}{l}14.3 \\
19.5 \\
14.1\end{array}$ & $\begin{array}{c}\text { gm. per } k \\
21.1 \\
15.4 \\
19.7\end{array}$ & $\begin{array}{l}12.5 \\
23.7\end{array}$ & $\begin{array}{l}18.8 \\
16.5 \\
25.0\end{array}$ \\
\hline
\end{tabular}




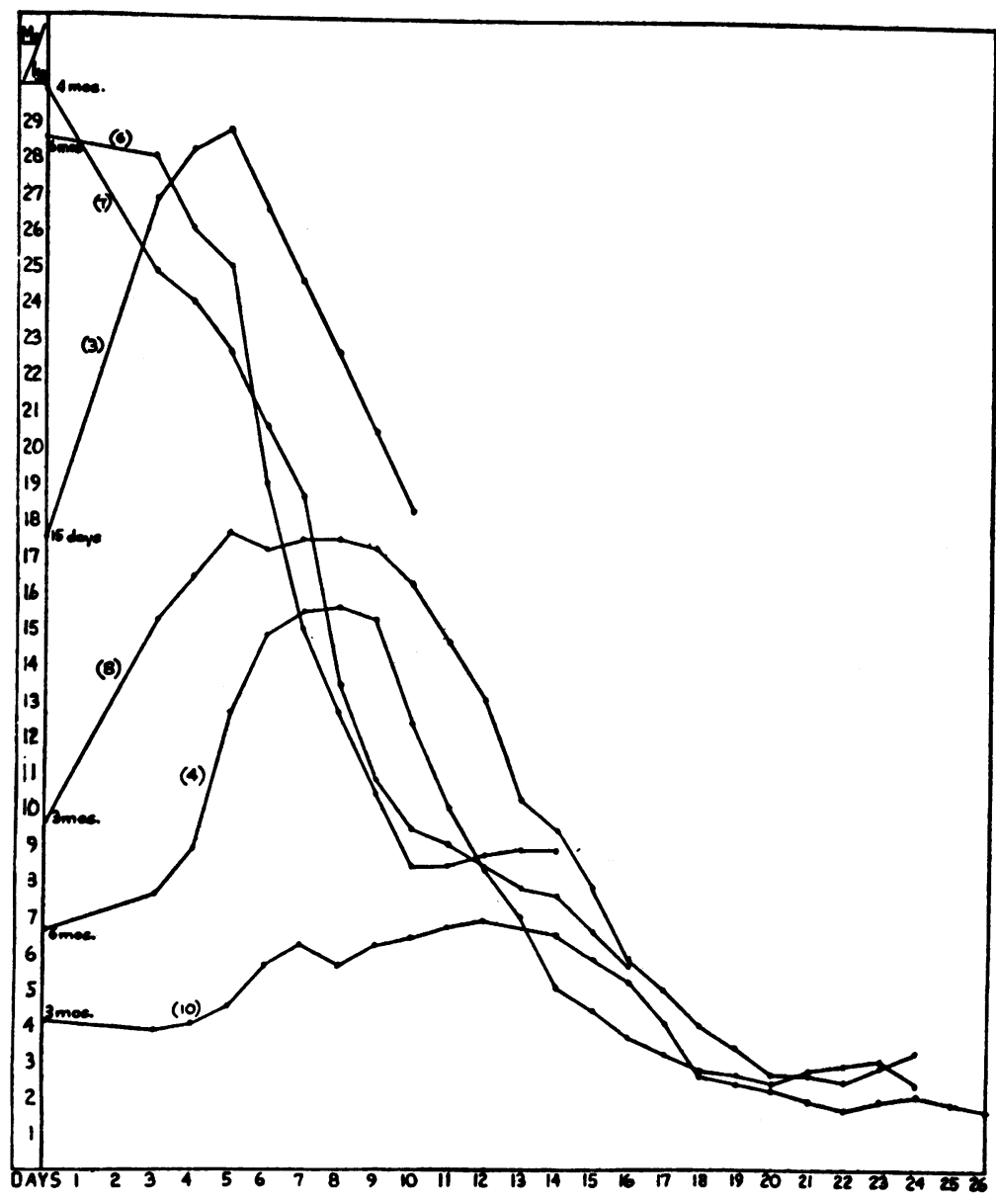

Fig. 3. Creatine Excretion After Withdrawal of Methyl Testosterone

been treated for 15 days, 2 for 3 months, 1 for 4 months, and 2 for 6 months. The daily excretions of creatine after withdrawal of treatment, computed by the method of "sliding averages" on 5-day periods, are shown in Figure 3. The levels of excretion prior to withdrawal (shown as the starting point of the curves) were calculated as averages for 10 days or more, immediately before discontinuing medication. In 4 patients, there was a marked increase in the creatine excretion, which reached a peak between the 4th and 14th days and then decreased (usually between the 5th and 10th). In 2 patients (No. 6 and No. 7) who showed exceptionally high outputs of creatine during treatment, there was an immediate decrease on withdrawal. The creatinine curves, which are not shown on the chart, showed the same trends as those of creatine but the changes were of less magnitude.

\section{Effect of the administration and withdrawal of testosterone propionate compared to that of methyl testosterone}

Certain authors (5, 9 to 14$)$ found that testosterone propionate caused no increase and at times a decrease in the excretion of creatine. Using the same methods as in the studies with methyl testosterone, we computed the creatine and creatinine output in 8 patients whom we treated with testosterone propionate for periods of 15 days and found that the excretion of both substances decreased during the first 6 or 7 days, and remained at the low levels for the remainder of the period. Both Albright and Kenyon 
kindly furnished us with data on 9 patients treated for longer periods, up to 2 months. These patients had not received creatine-free diets and had initial outputs much higher than ours. Reducing the base level of excretion to the same value as in our cases, we found they showed a trend similar to our patients, and that the low level of excretion persists throughout periods of treatment lasting 2 months. These findings are presented in Figure 4.

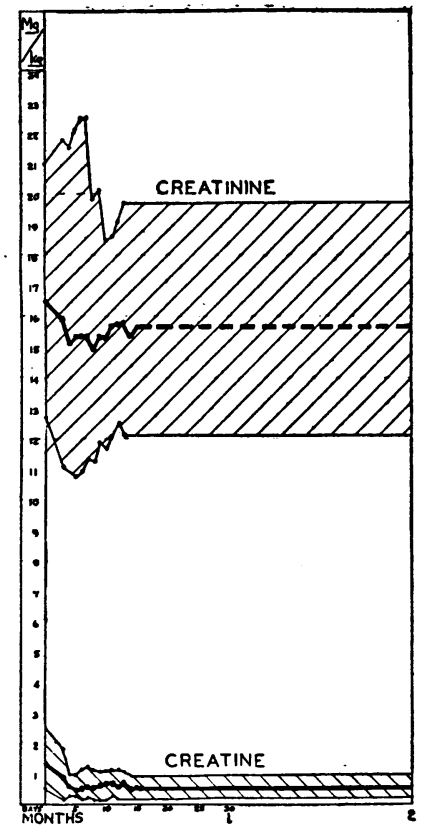

Fig. 4. Effect of Testosterone Propionate on Excretion of Creatine and Creatinine

After discontinuing testosterone propionate, 1 of our cases, 2 of Albright's, and 5 of Kenyon's showed a temporarily increased excretion of both creatine and creatinine, similar to that which occurred after the withdrawal of methyl testosterone. Kenyon and Albright (personal communication) have both noted this "rebound."

\section{Combined effect of methyl testosterone and testosterone propionate}

Since methyl testosterone increases and testosterone propionate depresses slightly the excretion of creatine, combined treatment with both substances was carried out to determine whether there was a true antagonistic effect. A patient treated with $25 \mathrm{mgm}$. methyl testosterone daily for 36 days showed a constantly increasing output of both creatine and creatinine. During the next 14 days, testosterone propionate in doses of $25 \mathrm{mgm}$. daily was injected intramuscularly in addition to the oral administration of methyl testosterone. This caused no decrease in the excretion of creatine or creatinine. Albright has made a similar observation on a patient with Cushing's syndrome.

\section{Effect of methyl testosterone given intramuscularly}

The question naturally arose whether or not the difference in the effects of methyl testosterone given by mouth and testosterone propionate given intramuscularly was due to the route of administration. In order to answer this, 3 patients were treated by intramuscular injections of methyl testosterone dissolved in oil. Increase in the excretion of creatine and creatinine occurred in the same manner as when the drug was given orally.

\section{Comparison of the creatinuria induced by thyroid with that caused by methyl testosterone}

It seemed worth while to compare the creatinuria which occurs in the treatment of hypothyroid patients with desiccated thyroid with that which is induced by methyl testosterone. For this purpose, we have analyzed data collected during the treatment of hypothyroid children and previously reported by us (15), together with some from a number of our patients studied subsequently. These children were of approximately the same age as those whom we have treated with methyl testosterone. Our findings are essentially in accord with those of others (16 to 19) in respect to the general effect of thyroid on the excretion of creatine and creatinine. Figure 5 is constructed along the same plans as Figure 2 and should be compared with the latter to show the striking differences in the effects of thyroid and of methyl testosterone. The shaded areas show the range of variations according to our data and the central lines represent approximately the general trend of excretion under continuous oral therapy. (There are of course considerable variations in the individual curves dependent partly upon the intensity of dosage with thyroid and the rapidity with which the dose is increased.) 


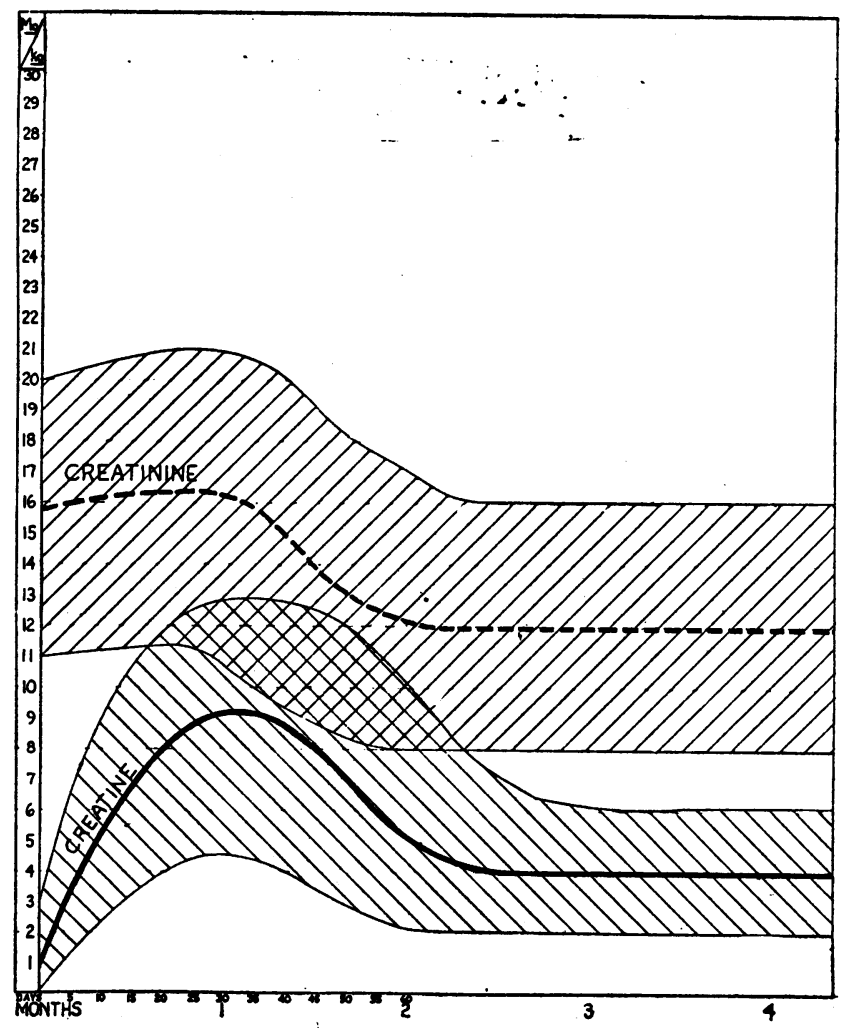

Fig. 5. Creatine-Creatinine Excretion during Thyroid Treatment of Hypothyroid Children

In general, with continuous treatment with thyroid in doses sufficient to correct the deficiency, there is an abrupt increase in the excretion of creatine within the first 2 or 3 days of treatment, without a latent period or initial decrease. The peak of excretion is reached between the 10th and 30th day. After this, there is a decline in the output until the 40th to 60th day when the amount of creatine excreted may be approximately within the range encountered in normal children, but is, nevertheless, somewhat higher than before the institution of therapy..$^{3}$ The effect of thyroid on the output of creatinine is different. During the period when the excretion of creatine is increasing rapidly, there is little, if any, increase in the output of creatinine. Later, the creatinine excretion decreases to a level below

\footnotetext{
- Shorr (personal communication) has found that occasionally the excretion of creatine remained elevated as long as one year. If sufficient thyroid is given to maintain the patient in a state of hyperthyroidism, the elevation may persist.
}

that found before treatment, suggesting an alteration in the equilibrium between creatine and creatinine.

When thyroid treatment is discontinued at a time when there is still a large output of creatine, there is a gradual decrease in the excretion beginning immediately, without the temporarily increased excretion encountered at times on withdrawing methyl testosterone.

\section{Effect of methyl testosterone on a hypothyroid patient}

Although the creatine and creatinine excretion appeared to be influenced quite differently by thyroid and by methyl testosterone, it seemed of interest to study the effect of methyl testosterone in a hypothyroid patient. Accordingly, thyroid treatment was discontinued for a period of 4 months in a cretin of 27 years. At the end of this time, her B.M.R. had reached a base level of -22 to -27 per cent, her serum cholesterol was 328 to $343 \mathrm{mgm}$. per cent, the 
average daily excretion of creatine was $31 \mathrm{mgm}$., of creatinine $672 \mathrm{mgm}$. Treatment for 35 days with daily doses of $25 \mathrm{mgm}$. methyl testosterone by mouth had effects on the excretion of creatine and creatinine identical to those observed in patients who were not hypothyroid. During the first 10 days, the excretion of both substances was decreased. There then occurred a progressive increase during the rest of the period. At the end of the period, the output of creatine was $270 \mathrm{mgm}$. per day and of creatinine $843 \mathrm{mgm}$. per day. The serum cholesterol remained unchanged during the administration of methyl testosterone and irregular elevations of the B.M.R. up to -3 per cent were found. At this time, the patient was given 3 grains of desiccated thyroid daily in addition to the $25 \mathrm{mgm}$. dose of methyl testosterone. This caused a sharp increase of creatine to a peak of $781 \mathrm{mgm}$. per day between the 5 th and 7 th days, followed by a decrease to $634 \mathrm{mgm}$. per day between the 8 th and 10th days. The creatinine was not influenced, remaining 857 and $856 \mathrm{mgm}$. during these periods. The serum cholesterol dropped to 260 mgm. per cent and the B.M.R. rose gradually to +36 per cent.

\section{DISCUSSION}

In developing a hypothesis to account for the effects of methyl testosterone on the creatinecreatinine metabolism, the following facts must be taken into consideration:

1. With methyl testosterone, there is a definite latent period of 4 to 16 days before there occurs any increase in the excretion of creatine and creatinine. In some cases, during this time, there may be a slight decrease in the output of both substances.

2. The latent period is followed by a progressive rapid increase in the excretion of both creatine and creatinine until the 3rd to the 6 th months, after which the excretion continues on a high level or even increases at a slower rate.

3. The increase of creatine is relatively much greater than that of creatinine so the ratio of creatine

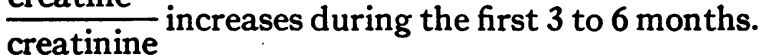

4. The high levels of excretion continue indefinitely as long as treatment is continued.
5. On discontinuing treatment, there is at times an abrupt increase in the creatine excretion followed by a decrease to the pretreatment level. There is a similar but smaller increase in the creatinine which also drops to nearly the pretreatment level when expressed in terms of mgm. per kgm. of body weight.

6. Testosterone propionate causes an initial slight decrease in both creatine and creatinine similar to that which occurs with methyl testosterone. However, this is not followed by an increased excretion. On discontinuing testosterone propionate, there is frequently a temporary increase in the output of creatine and creatinine, similar to that occurring with methyl testosterone. The simultaneous administration of testosterone propionate and methyl testosterone does not inhibit the effect of the latter.

7. The creatinuria induced in hypothyroid patients by thyroid treatment differs from that produced by methyl testosterone in a number of important respects; (a) there is little, if any, latent period and no initial decrease; $(b)$ the creatinuria is only temporary, the excretion decreasing to nearly normal levels after 30 to 60 days; $(c)$ the creatinine excretion tends to decrease rather than increase; (d) there is no temporarily increased excretion of creatine on discontinuing thyroid treatment.

8. Methyl testosterone causes creatinuria in untreated hypothyroid patients.

Relatively little is known concerning the normal creatine-creatinine metabolism. Creatine is probably synthesized largely by the combination of arginine and glycine to form guanidoacetic acid which in turn is methylated by some agent such as methionine or choline. The exact site of the synthesis is not known. Earlier work (20) on the synthesis of creatine with tissue slices suggests that guanidoacetic acid may be synthesized in the kidney and then methylated to creatine by the liver. About 98 per cent of all the creatine in the body is found in the muscles. In the muscles, part of the creatine occurs as phosphocreatine which is probably intimately bound in the protoplasm while part may be stored as free creatine. In normal adults and in slowly growing dwarfed children, creatine is almost entirely converted before excretion to 
its anhydride, creatinine. In young, rapidly growing children there is a considerable output of creatine as well as creatinine. Where the conversion to creatinine occurs is not known.

An increased excretion of creatine might depend theoretically upon the following changes in the normal mechanism:

A. Increased synthesis of creatine.

B. Destruction or increased catabolism of muscles. (This probably accounts for the creatinuria occurring in muscular dystrophies and atrophies, in starvation, and during wasting diseases and fevers.)

C. Decreased storage capacity of the muscles, releasing supplies of creatine already present. (Associated with this there might be diminished ability to fix creatine as phosphocreatine in the muscles.)

D. Diminished ability to convert creatine into creatinine.

E. Increased permeability of the kidney to creatine.

It is obvious that the study of changes in creatine metabolism should include the determination of the concentration of this substance in the muscles, the liver, and the blood, as well as its output in the urine. We hoped to make such studies on animals but have so far failed to produce a significant creatinuria with methyl testosterone in rats, guinea pigs, rabbits, or pigs. However, a number of deductions can be made from the clinical studies we have reported.

Most of the possible causes of increased creatinuria mentioned above can be excluded as explanations of the effect of methyl testosterone. The output of both creatine and creatinine is increased by the administration of this substance. Instead of destruction or increased catabolism there occurs an increased building of muscle tissue. However, the increased output of creatinine cannot be accounted for by increase in the total muscle mass because (1) the creatinine excretion was increased at times as much as $\mathbf{5 0}$ to 75 per cent which was obviously much greater than the increase in muscle bulk; (2) after discontinuing treatment the creatinine coefficient (mgm. creatinine per $\mathrm{kgm}$. of body weight) decreased. A decrease in the capacity of the muscles to store creatine or a lowering of the barrier permitting its release from these reservoirs would cause only a temporary creatinuria such as that which occurs with thyroid treatment. The creatinuria cannot be accounted for by a decrease in the conversion of creatine into creatinine. If this were the case, the creatinine excretion would decrease inversely with the increased creatine output and there would be no change in the total creatine-creatinine excretion. There is no evidence for a lowering of the renal threshold. Furthermore, others (2) have found that methyl testosterone caused an elevation of the creatine content of the blood. The fact that methyl testosterone causes a great increase in the excretion of both creatine and creatinine which continues indefinitely as long as treatment is continued (over 3 years according to our observation) can be explained only on the assumption that there is an increased synthesis of creatine. The possibility that methyl testosterone might affect the creatine metabolism through the thyroid gland is excluded by the fact that it produces creatinuria in an untreated cretin.

It is apparent that the mechanism of the creatinuria which occurs with thyroid medication is quite different from that with methyl testosterone. In a previous paper (15), we suggested that thyroid treatment may cause a release of stores of creatine from the tissue and possibly also an increased catabolism of muscle. The fact that treatment of the hypothyroid patient causes creatinuria for 30 to 60 days, while in normal children the effects of desiccated thyroid last for a much shorter period, suggests that the stores are greater and less rapidly depleted in the hypothyroid than in the normal. When treatment of a hypothyroid patient has been continued for a long period until the creatine and creatinine excretion have become stabilized, the output of creatine is often somewhat higher and that of creatinine somewhat lower than in the pretreated period, suggesting that the conversion of creatine into creatinine is diminished.

In considering the action of methyl testosterone, it still remains to explain the latent period during which there is at times a decrease in the excretion of creatine and creatinine and the increased excretion which sometimes occurs temporarily after treatment is discontinued. Both of these phenomena are seen with testo- 
sterone propionate as well as with methyl testosterone. These findings suggest that when treatment is begun the barrier for the release of creatine from the tissues is raised, thereby increasing the storage capacity of the reservoirs. This causes a latent period during which there may even be a temporary decrease in the output of creatine and creatinine. Finally, with the increased synthesis caused by methyl testosterone, the reservoirs become filled to overflowing and the excretion increases. On the other hand, testosterone propionate does not cause increased synthesis and no overflow occurs. When treatment with either methyl testosterone or testosterone propionate is discontinued, the reservoir barrier is again lowered, and creatine pours out temporarily. That testosterone propionate has an effect on creatine storage has been demonstrated by investigators (21) who studied the effect of testosterone propionate injections on the excretion of creatine by mature male rabbits. Creatine excretion was decreased. Paired muscle analyses indicated increased creatine storage in the muscles. Other workers (22), however, found no significant difference in the muscle creatine content of normal and castrate rats with and without androgen treatment but with a liberal supply of exogenous creatine.
THE EFFECTS OF VARIOUS ANDROGENIC STEROIDS

$$
\begin{aligned}
& \text { AND OTHER COMPOUNDS ON } \\
& \text { CREATINE EXCRETION }
\end{aligned}
$$

In the previous section, we have developed the hypothesis that methyl testosterone causes an increased synthesis of creatine while testosterone propionate does not. However, both methyl testosterone and testosterone propionate may increase, in some cases, the amount of creatine stored and those reserve stores are released when treatment is discontinued.

In conjunction with studies on nitrogen retention, we have investigated the effects on the excretion of creatine of a number of steroids having the chemical structure of androgens. The results are shown in Table II.

Of the 12 compounds studied, creatinuria occurred only with 17-methyl testosterone, 17methyl androstenediol, and 17-methyl androstanediol.4 There was no correlation between

\footnotetext{
- Dr. Samuel H. Bassett and Dr. Henry Keutmann (personal communication) were the first to observe creatinuria induced by 17-methyl androstanediol. Their patient was an adult, Chinese eunuch. We are at a loss to explain why creatinuria did not result in one of our patients, a boy aged 9 , but could be induced in another boy aged 12. The nitrogen retention observed with this drug was so small as to be hardly significant.
}

TABLE II

\begin{tabular}{|c|c|c|c|c|c|c|c|}
\hline Chemical name & Common name & $\begin{array}{l}\text { No. } \\
\text { of } \\
\text { cases }\end{array}$ & Dose & $\begin{array}{l}\text { Duration } \\
\text { of } \\
\text { treatment }\end{array}$ & $\begin{array}{c}N-\text { re- } \\
\text { ten- } \\
\text { tion }\end{array}$ & $\begin{array}{c}\text { In- } \\
\text { creased } \\
\text { excre- } \\
\text { tion } \\
\text { of } 17- \\
\text { keto- } \\
\text { steroids }\end{array}$ & $\begin{array}{l}\text { Cre- } \\
\text { atin- } \\
\text { uria }\end{array}$ \\
\hline $\begin{array}{l}\text { Androstane-ol }(3 \alpha) \text {-one }(17) \\
\Delta_{5} \text { Androstene-ol }(3 \beta) \text {-one }(17) \text { acetate }(17)\end{array}$ & $\begin{array}{l}\text { Androsterone } \\
\text { Dehydroisoandrosterone } \\
\text { acetate }\end{array}$ & $\begin{array}{l}1 \\
2\end{array}$ & $\begin{array}{l}\text { mgm. } \\
20 \text { i.m. } \\
10-40 \text { i.m. }\end{array}$ & $\begin{array}{l}\text { days } \\
10 \\
18,13\end{array}$ & $\begin{array}{l}0 \\
0\end{array}$ & $\dot{t}$ & $\begin{array}{l}0 \\
0\end{array}$ \\
\hline $\begin{array}{l}\Delta_{4} \text { Androstenedione }(3,17) \\
\Delta_{4} \text { Androstene-one }(3) \text { ol }(17 \alpha) \\
\Delta_{4} \text { Androstene-one }(3) \text { ol }(17 \alpha) \text {-propionate } 17\end{array}$ & $\begin{array}{l}\text { Testosterone } \\
\text { Testosterone propionate }\end{array}$ & $\begin{array}{l}1 \\
2 \\
6\end{array}$ & $\begin{array}{l}20 \text { i.m. } \\
20 \text { i.m. } \\
25 \text { i.m. }\end{array}$ & $\begin{array}{l}12 \\
18,16 \\
15 \text { or } \\
\text { more }\end{array}$ & $\begin{array}{l}0 \\
+ \\
+\end{array}$ & $\begin{array}{l}+ \\
+ \\
+\end{array}$ & $\begin{array}{l}\mathbf{0} \\
\mathbf{0} \\
\mathbf{0}\end{array}$ \\
\hline $\begin{array}{l}\Delta_{5} \text { Androstenediol }(3 \beta, 17 \alpha) \\
\Delta_{5} \text { Androstenediol }(3 \beta, 17 \alpha) \text { diacetate }(3,17) \\
\text { Androstanediol- }(3 \alpha, 17 \alpha) \text {-diacetate }(3,17)\end{array}$ & & $\begin{array}{l}1 \\
2 \\
2\end{array}$ & $\begin{array}{l}10 \text { i.m. } \\
45 \text { i.m. } \\
20-40 \text { i.m. }\end{array}$ & $\begin{array}{c}13 \\
16,23 \\
16 \text { to } 24\end{array}$ & $\begin{array}{l}0 \\
\pm \\
\pm\end{array}$ & $\stackrel{+}{+}$ & $\begin{array}{l}\mathbf{0} \\
\mathbf{0} \\
\mathbf{0}\end{array}$ \\
\hline 17-Methyl $\Delta_{4}$ androstene-one(3)ol(17 $\left.\alpha\right)$ & 17-Methyl testosterone & 12 & 25 (oral) & 16 to 18 & $t$ & 0 & - \\
\hline 17-Methyl $\Delta_{\mathrm{B}}$ androstene-diol $(3 \beta, 17 \alpha)$ & & & $\begin{array}{l}30-50 \text { (oral) } \\
+10 \text { i.m. }\end{array}$ & 16 to 45 & \pm & $\mathbf{0}$ & + \\
\hline 17-Methyl androstanediol-3( $\alpha), 17(\alpha)$ & & $\left\{\begin{array}{l}1 \\
1\end{array}\right.$ & $\begin{array}{l}50 \text { (oral) } \\
50 \text { (oral }\end{array}$ & $\begin{array}{l}28 \\
20\end{array}$ & $\begin{array}{l} \pm \\
\pm\end{array}$ & $\begin{array}{l}0 \\
0\end{array}$ & $\begin{array}{l}0 \\
+\end{array}$ \\
\hline 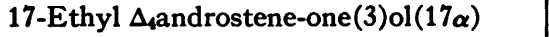 & 17-Ethyl testosterone & 2 & 40 i.m. & 20 & 0 & $\mathbf{0}$ & $\mathbf{0}$ \\
\hline
\end{tabular}

Effect of various steroids on $N$-retention and on the excretion of 17-ketosteroids and of creatine 


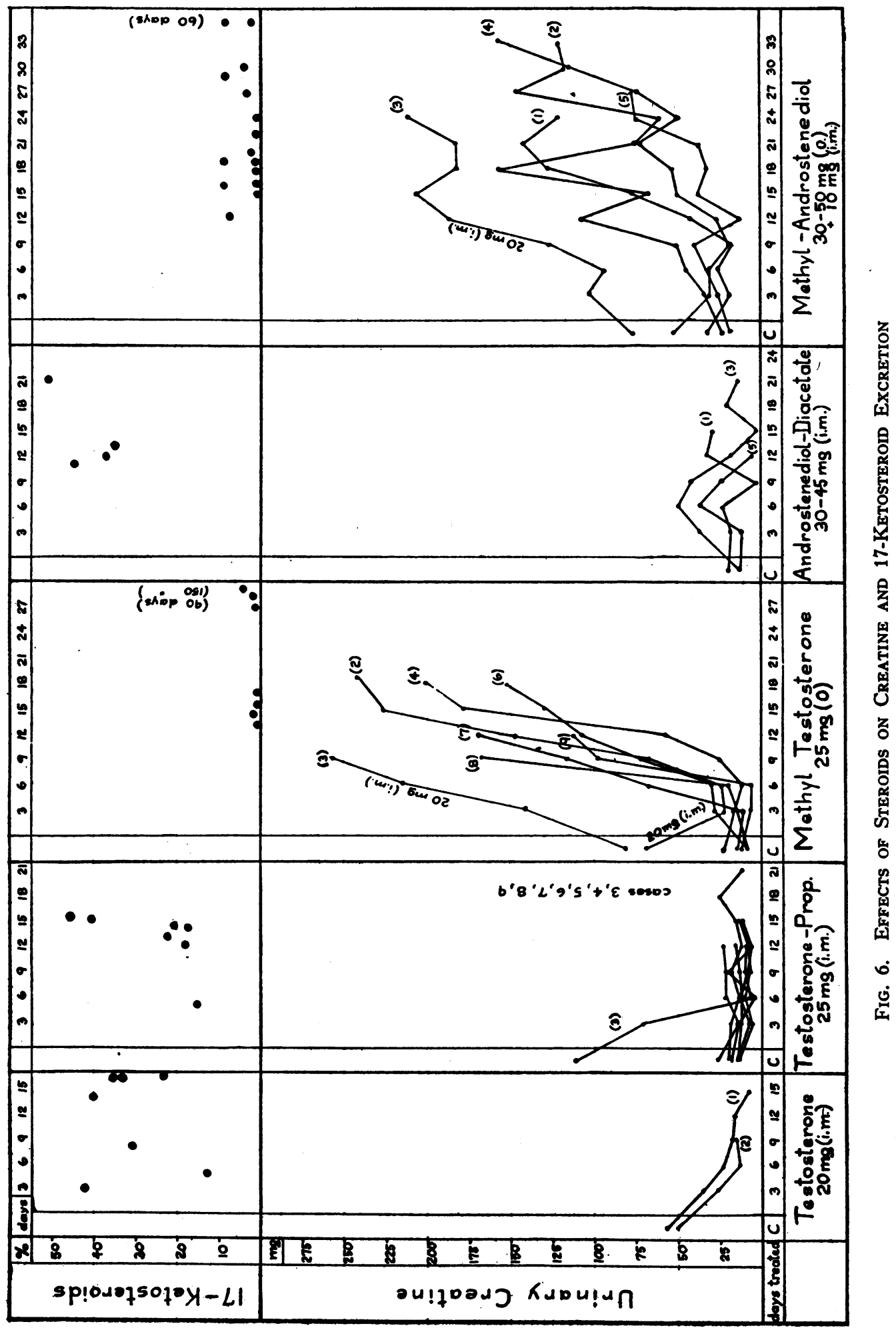


the ability of a compound to cause the retention of nitrogen and the production of creatinuria as shown by the effects of testosterone and testosterone priopionate on the one hand, and 17 methyl androstenediol on the other. (With both methylated and non-methylated compounds of androstenediol and androstanediol the amount of nitrogen retained is so small as to be of doubtful significance.) The creatinuria found with methyl androstenediol seemed to be essentially the same as that caused by methyl testosterone except that it occurred more gradually. This is shown in Figure 6. The fact that methylation has been demonstrated to be an essential step in the synthesis of creatine suggested that the methyl side chains at the 17position might be responsible for the increased production of creatine. It is obvious, however, that the synthesis could not be attributed to a direct transfer of the $17-\mathrm{CH}_{3}$ because $25 \mathrm{mgm}$. of methyl testosterone daily would not supply sufficient $\mathrm{CH}_{3}$ for the production of the large amounts of creatine (often as much as 300 to $700 \mathrm{mgm}$.) excreted daily. The second possibility that must be considered is that 17-methyl testosterone, 17-methyl androstenediol, and 17methyl androstanediol act as transmethylating catalysts. In this way, the compounds would act as "carriers" of methyl derived from some other source and it is necessary to presuppose a "shuttle action" of the $\mathrm{CH}_{3}$ back and forth between free testosterone and methyl testosterone, or androstenediol and methyl androstenediol. This possibility can be excluded, because were this the case, testosterone, androstenediol, and androstanediol would act as methylating agents equally as well as their 17-methyl derivatives.

A third possibility must be considered. Even though the 17-methyl compounds themselves cannot be considered as the immediate methylating agents in the synthesis of creatine, it is possible that in the body, the steroid molecule is split at some point to give a simpler compound which serves as a methylating catalyst. The study of the excretion of the 17-ketosteroids during the administration of various androgens supplies evidence that 17-methyl compounds are catabolized differently from non-methylated androgens. Frame and we (24) have reported ${ }^{\mathrm{s}}$ that the administration of 17-methyl testosterone and of 17-methyl androstenediol caused no increase in the excretion of 17-ketosteroids, whereas testosterone, testosterone propionate, and androstenediol diacetate were excreted at least partly as 17-ketosteroids in amounts representing 20 to 50 per cent of the doses administered (see Figure 6). Apparently, the introduction of $\mathrm{CH}_{3}$ as a side chain at the 17 position prevents oxidation from a hydroxyl to a ketone group at the $\mathbf{1 7}$ position. Furthermore, biologic assays of the urine (23) have shown that active androgens are recovered after the administration of testosterone propionate but are not found with methyl testosterone.

Although the findings we have discussed suggest that the 17-methyl compounds may be degraded and excreted in a manner different from non-methylated androgens and that some compounds split from the molecule may act as methylating catalysts, we have no clue as yet to the structure of such compounds. We are now studying the effect of a number of simpler methylated ring compounds on creatine excretion. These investigations will be reported later.

\section{SUMMARY}

Observations are reported on the effect of steroids of the androsterone-testosterone series on the excretion of creatine and creatinine. A latent period of from 4 to 16 days after beginning treatment with methyl testosterone is followed by a progressive increase in the excretion of both creatine and creatinine until the third to sixth months, after which the excretion continues on a high level which is maintained indefinitely as long as treatment is continued. This creatinuria seems to be explained best by assuming that there is an increased synthesis of creatine. Testosterone propionate does not cause an increased synthesis of creatine, but both methyl testosterone and testosterone propionate may increase the amount of creatine stored and these stores are released when treatment is discontinued. The creatinuria induced in hypothyroid

\footnotetext{
5 The 17-ketosteroids were determined by Dr. Elizabeth G. Frame of the Brady Urological Institute by the method described by her recently (Endocrinology, 1944, 34, 175).
} 
patients by thyroid treatment differs from that induced by methyl testosterone in a number of important respects, which are discussed. Methyl testosterone causes creatinuria in untreated hypothyroid patients. Of 12 steroid compounds studied, creatinuria occurred only with 17-methyl testosterone, 17-methyl androstenediol, and 17methyl androstanediol. The possible function of the methyl side chain at the 17 position of the steroid ring system for the increased production of creatine is discussed.

The methyl testosterone (Metandren) and the testosterone propionate (Perandren) were kindly supplied by the Ciba Pharmaceutical Products, Inc., Summit, New Jersey. We wish to express our appreciation to Drs. Ernst Oppenheimer and C. R. Scholz of this company for their valuable advice and interest in this work, and especially for preparing the rarer steroid compounds used.

Diets were planned by the dietary department of the Johns Hopkins Hospital. We wish to thank Mr. Edward Smetana (now in the U. S. Army) and Miss Ilse A. Fried for their assistance in the creatine determinations.

\section{BIBLIOGRAPHY}

1. Wilkins, L., Fleischmann, W., and Howard, J. E., Creatinuria induced by methyl testosterone in the treatment of dwarfed boys and girls. Bull. Johns Hopkins Hosp., 1941, 69, 493.

2. Samuels, L. T., Henschel, A. F., and Keys, A., Influence of methyl testosterone on muscular work and creatine metabolism in normal young men. J. Clin. Endocrinol., 1942, 2, 649.

3. Tager, B. N., Creatine metabolism and methyl testosterone. J. Clin. Endocrinol., 1943, 3, 185.

4. Werner, S. C., and West, R., Nitrogen retention, creatinuria and other effects of the treatment of Simmonds' disease with methyl testosterone. J. Clin. Invest., 1943, 22, 335.

5. Albright, F., Personal communication.

6. Kenyon, A. T., Personal communication.

7. Browne, J. S. L., Personal communication.

8. Benedict, F. G., and Myers, V. C., The determination of creatine and creatinine. Am. J. Physiol., 1907, $18,397$.

9 Kenyon, A. T., Sandiford, I., Bryan, A. H., Knowlton, K., and Koch, F. C., The effect of testosterone propionate on nitrogen, electrolyte, water and energy metabolism in eunuchoidism. Endocrinology, 1938, 23, 135.

10. Kenyon, A. T., Knowlton, K., Sandiford, I., Koch, F. C., and Lotwin, G., A comparative study of the metabolic effects of testosterone propionate in normal men and women and in eunuchoidism. Endocrinology, 1940, 26, 26.

11. Kenyon, A. T., Knowlton, K., Lotwin, G., Munson, P. L., Johnston, C. D., and Koch, F. C., Comparison of metabolic effects of testosterone propionate with those of chorionic gonadotropin. J. Clin. Endocrinol., 1942, 2, 685.

12. Kenyon, A. T., Knowlton, K., Sandiford, I., and Fricker, L., Metabolic effects of testosterone propionate in Addison's disease. J. Clin. Endocrinol., 1943, 3, 131.

13. Knowlton, K., Kenyon, A. T., Sandiford, I., Lotwin, G., and Fricker, R., Comparative study of metabolic effects of estradiol benzoate and testosterone propionate in man. J. Clin. Endocrinol., 1942, 2, 671.

14. Sandiford, I., Knowlton, K., arid Kenyon, A. T., Basal heat production in hypogonadism in men and its increase by protracted treatment with testosterone propionate. J. Clin. Endocrinol., 1941, 1, 931.

15. Wilkins, L., Fleischmann, W., and Block, W., Hypothyroidism in childhood. II. Sensitivity to thyroid medication as measured by the serum cholesterol and the creatine excretion. J. Clin. Endocrinol., $1941,1,14$.

16. Shorr, E., Richardson, H. B., and Mansfield, J. S., Influence of thyroid administration on creatin metabolism in myxedema of adults. Proc. Soc. Exper. Biol. and Med., 1935, 32, 1340.

17. Carson, D. A., Creatine excretion in artificial hyperthyroidism. Proc. Soc. Exper. Biol. and Med., 1927-1928, 25, 382.

18. Fan, C., Creatine and creatinine metabolism in hypothyroidism. J. Pediat., 1941, 18, 57.

19. Poncher, H. G., Bronstein, I. P., Wade, H. W., and Ricewasser, J. C., Creatine metabolism in hypothyroid infants and children: Further observations. Am. J. Dis. Child., 1942, 63, 270.

20. Borsook, H., and Dubnoff, J. W., Synthesis of glycocyamine in rat kidney and mechanism of creatine synthesis in vivo. Science, 1940, 91, 551.

21. Williamson, M., and Gulick, A., Influence of testosterone on distribution and excretion of creatine. Endocrinology, 1941, 28, 654.

22. Coffman, J. R., and Koch, F. C., The effect of testosterone propionate on induced creatinuria in rats. J. Biol. Chem., 1940, 135, 519.

23. Dorfman, R. I., and Hamilton, J. B., Concerning the metabolism of testosterone to androsterone. J. Biol. Chem., 1940, 133, 753.

24. Frame, E. G., Fleischmann, W., and Wilkins, L., The influence of a number of androgenic steroids on the urinary excretion of neutral 17-ketosteroids. Bull. Johns Hopkins Hosp., 1944, 75, 95. 